\title{
Study on Thin Airfoil Theory and Performance Test of Elliptical Wing as Compared to Model Mosquito Wing and NACA 64A012 Mod Airfoil
}

\author{
Nesar Ali, Mostafizur R. Komol, and Mohammad T. Saki
}

\begin{abstract}
Thin airfoil theory is a simple conception of airfoils that describes angle of attack to lift for incompressible, inviscid flows. It was first devised by famous GermanAmerican mathematician Max Munk and therewithal refined by British aerodynamicist Hermann Glauertand others in the 1920s. The thin airfoil theory idealizes that the flow around an airfoil as two-dimensional flow around a thin airfoil. It can be conceived as addressing an airfoil of zero thickness and infinite wingspan. Thin airfoil theory was particularly citable in its day because it provided a well-established theoretical basis for the following important prominence of airfoils in two-dimensional flow like i) on a symmetric shape of airfoil which center of pressure and aerodynamic center remain exactly one quarter of the chord behind the leading edge, ii) on a cambered airfoil, the aerodynamic center lies exactly one quarter of the chord behind the leading edge and iii)the slope of the lift coefficient versus angle of attack line is two pi $(\pi)$ units per radian. The fundamental equation of Prandtl's lifting-line theory; simply states that the geometric angle of attack is equal to the sum of the effective angle plus the induced angle of attack. And also omitted the theory of elliptical wing theory which indicates that the Elliptical wing has better flight performance than any other airfoil. In this experiment we made a model of elliptical wing and test in wind tunnel to get experimental value. We also analyze the model in simulation software for further knowledge. Comparing this practical and experimental value to other airfoil like Mosquito wing and NACA 64A012 airfoil for further research.
\end{abstract}

Index Terms-Inviscid Flows; Thin Airfoil; Symmetric Airfoil; Infinite Wingspan; Effective Angle; Lift Coefficient.

\section{INTRODUCTION}

Aero-dynamics is the perusal of the dynamics associated with the motions of air over a moving or stationary object. When an aircraft or airfoil accelerates down the runway to take off, it produces a relative motion between the air and the aircrafts wings or adjacent body of contact. It is this rip of airflow over and below the wings, originated by the aircrafts forward or backward motion, which produces lift and consequently makes all forms of powered flight possible. Insect wings annex magnificent stability and high load-bearing capacity during flapping flight, glide, taxing and hover. Scientists have been caballed by them and have performed research for biomimetic applications. Because of

Published on April 28, 2018.

Md. Nesar Ali was with Chittagong University of Engineering \& Technology (e-mail: nesarali455@gmail.com)

Md. Mostafizur Rahman Komol was with Khulna University of Engineering \& Technology (e-mail: komolmostafizur@gmail.com)

Mohammad Takiuddin Saki was with Bangladesh Institute of Marine Technology (email: bimt.saki@gmail.com) their elevated flying characteristics, flying insects give researchers inspiration for biomimetic fabrications of insect's wing and many model aircraft wing. We also analyze the four basic principle forces acting on an aircraft in flight and insect's flying [1], [15].

Flight is the astonishment that has long been a part of the natural world. Birds fly and insect's flying not only by flapping their wings, but by gliding with their wings convoluted for long distances. Likewise, man-made aircraft bank on this philosophy to overcome the force of gravity and achieve enough flight. Lighter-than-air craft, such as the hot air balloon, dispense on the Buoyancy principle. [2]. Cambered and crooked airfoil exhibits little or no benefit over symmetric or well-proportioned airfoils in terms of the time averaged thrust coefficient and propulsive efficiency. This is because more thrust is produced in the down stroke but approximately the same amount less is produced in the upstroke on account of the effective increase in thickness of upper surface and gradually decreased in thickness on lower surface of the airfoil caused by the camber or cambered foil. [14]. The goal of this thesis paper is to hunt out that, among those which airfoil is the most suitable, subtle accuracy of geometrical shape and efficient to be used in a low-speed aircraft and having maximum lift with respect to minimum drag on the basis of their Lift-to-Drag ratio which is known as Aerodynamic efficiency (L/D), Lift coefficient, Drag coefficient and Moment coefficient under the discerned boundary conditions and the value of Mach number varies from 0.10 to 0.30 [10].

\section{THEORETICAL REDACTION}

\section{A. Thin Airfoil Theory}

Thin airfoil theory is based on the assumption that under certain conditions an airfoil section may be replaced by its mean camber line ( $\mathrm{mcl})$.

\section{Theoretical Assumption}

1. Airfoil is thin $\eta<<\mathrm{c}$;

2. Angles/slopes are small e.g. $\quad \sin \alpha \approx \alpha, \quad \cos \alpha \approx 1$, slope $\approx$ angle;

3. Airfoil only slightly disturbs free stream $u^{\prime}, v^{\prime} \ll<\infty$. [3]

\section{B. Experimental Observation}

If airfoil section of the same mcl but different thickness functions are tested experimentally at the same angle, it is found that the lift $\mathrm{L}$ and the point application of the lift for 
the different airfoil sections are practically the same provided that

a) Maximum airfoil thickness $(\mathrm{t} / \mathrm{c})$ is small;

b) Camber distribution $(\mathrm{z} / \mathrm{c}) \max =\mathrm{m}$ is small;

c) Angle of attack $(\alpha)$ is small;

This observation permitted the formulation of thin airfoil theory because it allowed the airfoil to be replaced by the $\operatorname{mcl}[3]$.

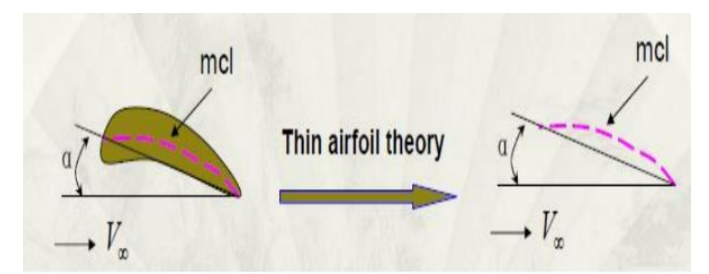

Fig. 1. Thin Airfoil Theory [3]

Therefore, in the thin airfoil theory the mcl (mean camber line) is replaced by a vortex sheet of varying strength $\gamma(\mathrm{s})$ such that the above conditions are satisfied and our aim is to determine this ' $\gamma$ ' distribution.

$$
\Gamma=\int \gamma d s
$$

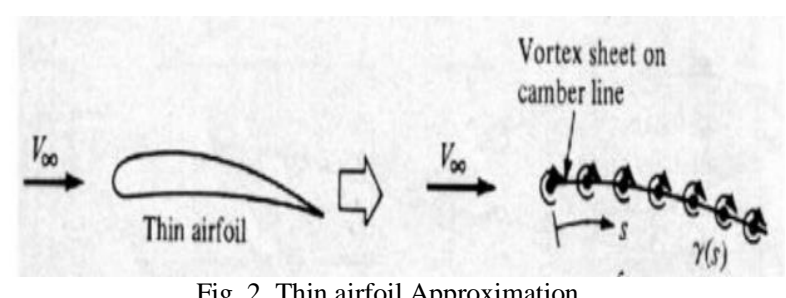

Fig. 2. Thin airfoil Approximation

The fundamental equation for thin airfoil theory is given below:

$$
\mathrm{V}_{\infty}\left(\alpha-\frac{d Z}{d x}\right)-\int_{0}^{C} \frac{\gamma(\xi) d \xi}{2 \pi(x-\xi)}=0 \quad(\text { for } 0<\mathrm{x}<\mathrm{c})
$$

After solving equation $\gamma(\xi)$ to satisfy;

a) The camber line is a streamline;

b) Kutta condition $\gamma(\mathrm{c})=0$ boundary conditions.

\section{Camber}

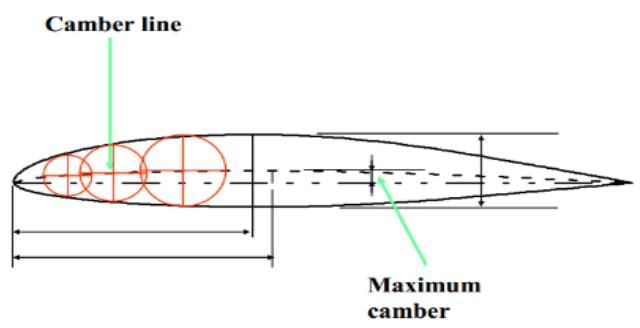

Fig. 3. Position of Maximum Camber

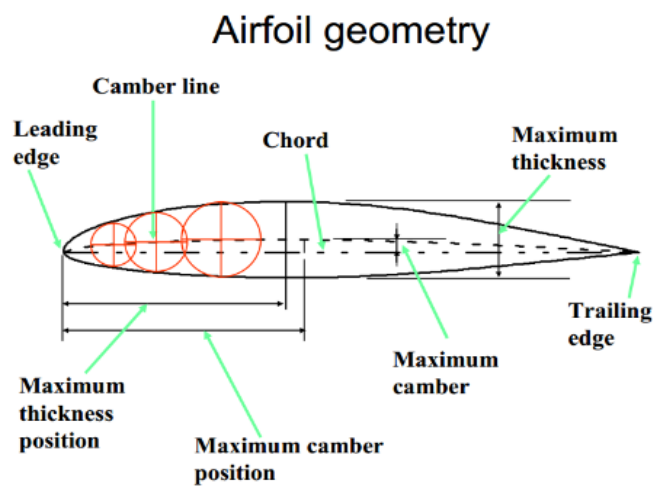

Fig. 4. Wing Geometry [4]

\section{Methods AND MATERIALS}

\section{A. Analytical Test of Elliptical Wing and Model Mosquito Wing}

The most important part of analytical studies is to select an airfoil. We select elliptical wing because further more studies of aerodynamics equation about finite wing theory we realize that elliptical wing has greater aerodynamics efficiency than any other wing. On the other hand, as proceeding our experiment we fabricate model wing of mosquito wing to analyze the practical result of insect wing flight in nature. We also fabricate model of NACA 64A012 mod airfoil for comparing those three values. The fabricated model wing may have a certain or a non-constant crosssection across the wing.

There are couple of ways to recite wing airfoil section:

1. Airfoil sketch

2. Airfoil sorting

The sketch and fabrication of the model airfoil is an intricate and lengthy as well as time consuming process which needs sagacity in fundamentals of aerodynamics knowledge. Since the fabricated airfoil further need to be ascertained by testing it in a wind tunnel [4], [12].

Elliptical wing, Mosquito wing \& NACA 64A012 airfoil Fabrication

We draw the pattern of Elliptical wing, Mosquito wing \& NACA 64A012 mod airfoil in 'SOLIDWORS' as we considered the top view of that wing as the cross-section of our wing. At the time of wing modelling \& fabrication we don't follow any conventional parameters subsequent to the airfoil geometrical shape. We just sketched and fabricated the Elliptical wing, Mosquito wing \& NACA 64A012 mod airfoil but all these three wing has demonstrated parameter like length is ' $171 \mathrm{~mm}$ ' and width is '94 mm' and the average height of these two in ' $3.2 \mathrm{~cm}$ '. Since those wing has a lot geometrical shape error but we tried to minimize that problem as our main target is to replicate those wing approximately look like an Elliptical wing, Mosquito wing and NACA 64A012 mod airfoil 


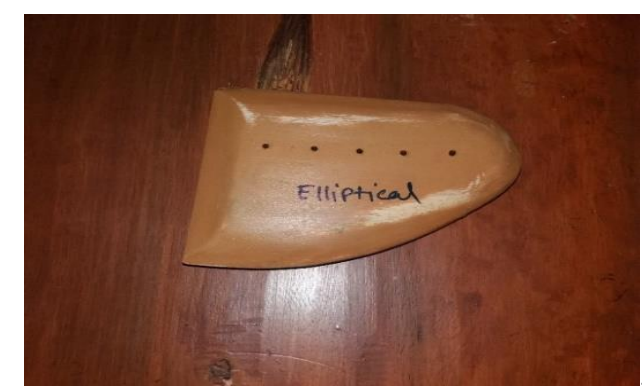

(a)

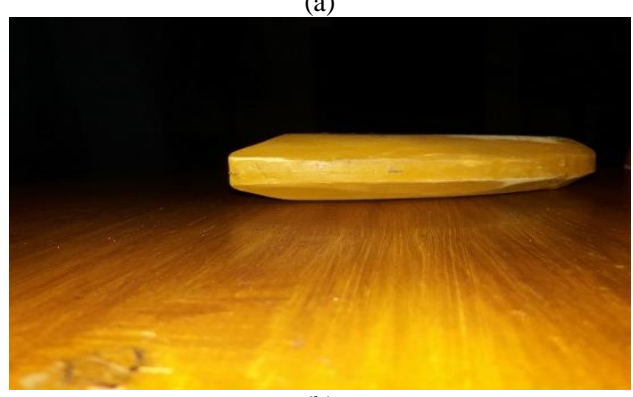

(b)

Fig. 5 (a,b). Elliptical Wing (model)

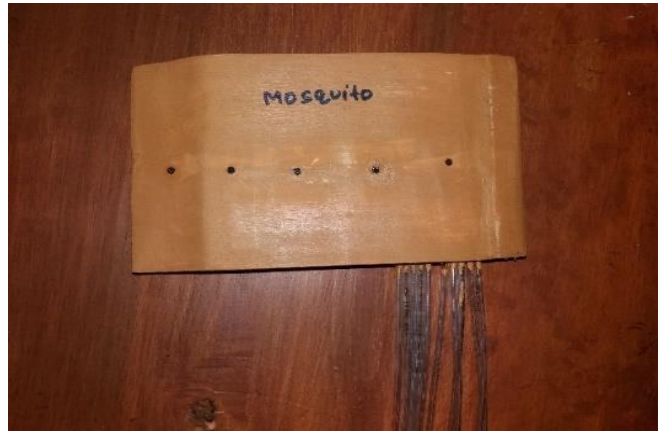

(a)

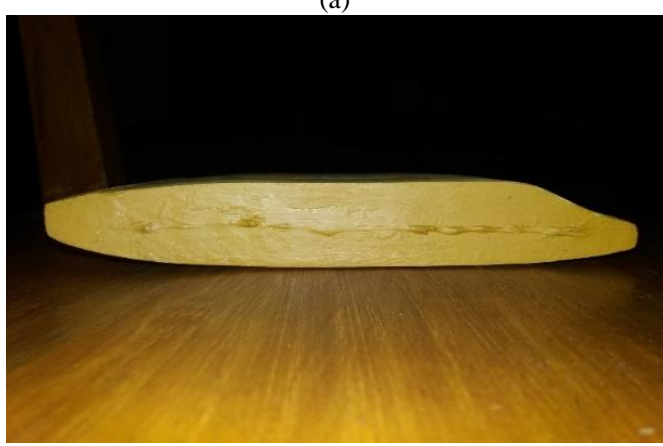

(b)

Fig. 6 (a,b). Mosquito wing (model)

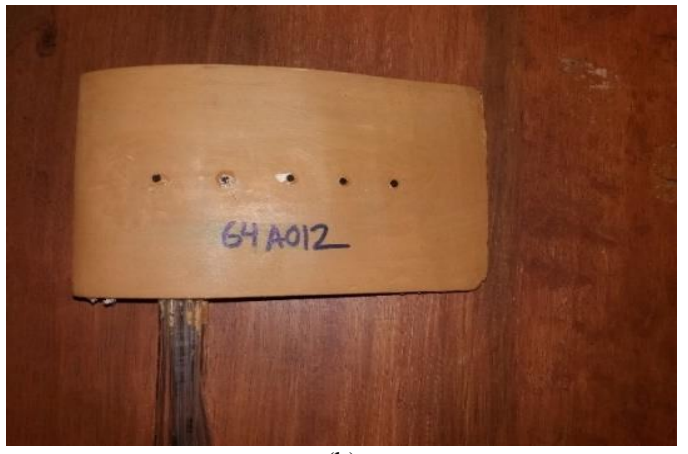

(b)

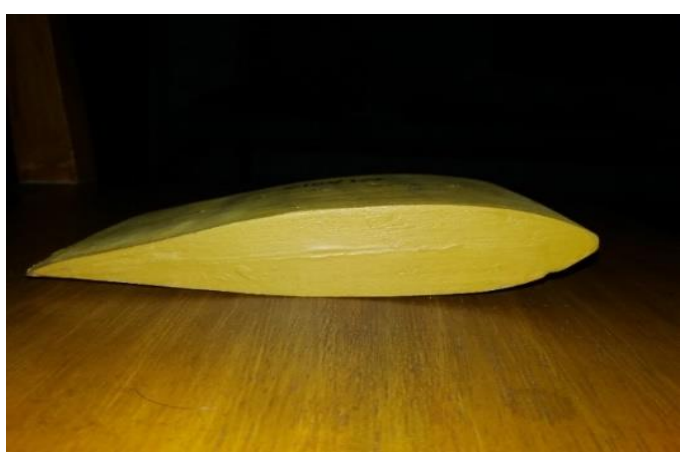

(b)

Fig. 7 (a,b). NACA 64A012 mod airfoil (model)

\section{B. Simulation Setup}

The model was made using the 'Curves using XYZ point' function. The SOLIDWORKS pattern with proper dimension of chord length and span of the wing as shown below figures.

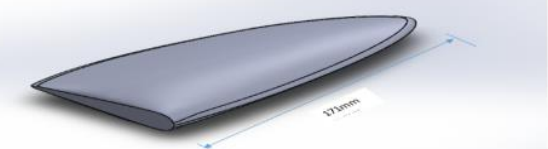

(a)

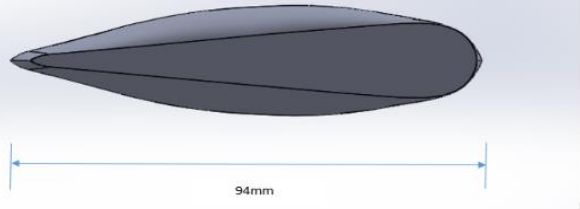

(b)

Fig. 8 (a,b). Schematic drawing Elliptical wing (model)

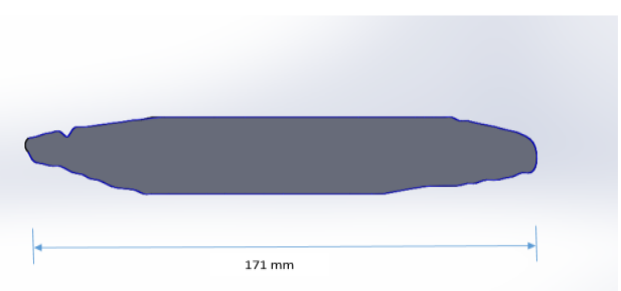

(a)

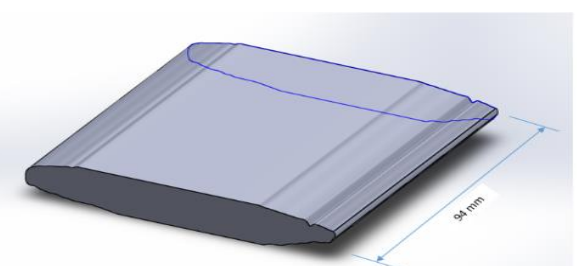

(b)

Fig. 9 (a,b). Schematic drawing Mosquito Wing (model) 


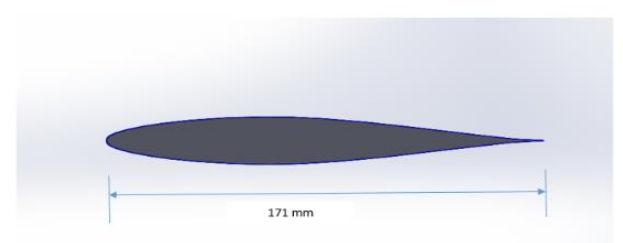

(a)

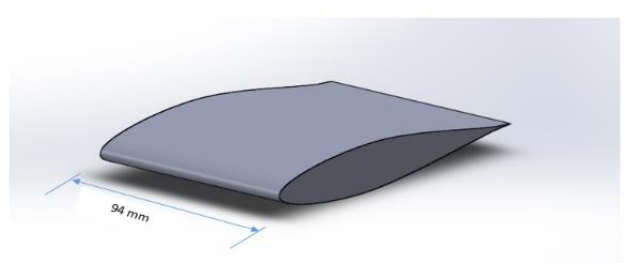

(b)

Fig. 10 (a, b). Schematic drawing NACA 64A012 mod Airfoil (model)

The pattern of NACA 64A012 mod airfoil (model) in SolidWorks was created from the data taken from UIUC airfoil database [5]. The simulation was ran using these parameters: Fluid was assumed incompressible and the flow was taken laminar.

Fluid: Air

Temperature: $298.2 \mathrm{~K}$

Pressure: $101325 \mathrm{~Pa}$

Air Velocity: $4.7 \mathrm{~m} / \mathrm{s}$

Air Density: $1.15 \mathrm{Kg} / \mathrm{m} 3$

Surface Area: $16074 \mathrm{~mm} 2$ or $0.016074 \mathrm{~m} 2$

Prototype Material: Beech wood (Gamahr)

The SOLIDWORKS software Flow Simulation is based upon the use of Cartesian-based meshes and automatic meshing system will create mesh in accordance with the specified minimum gap size, minimum wall thickness, and result resolution level [8].

\section{Experimental Procedure}

The important elements for experimental setup is to fabricate model prototype, an open-loop subsonic wind tunnel, a mass balance for measuring shearing forces and allows the orientation to be changed during the experiment, pressure taps and multi-tube manometer.

\section{Prototype}

A prototype model airfoil of NACA 64A012 mod, Elliptical wing \& Mosquito wing was built for wind tunnel experiment with the predefined chord length $(171 \mathrm{~mm})$ and span $(94 \mathrm{~mm})$ of each airfoil. The prototype was made in the workshop of Mechanical dept. of CUET. Beech wood (Gamahr) was used as material to make those airfoil model.

\section{E. Wind Tunnel Testing}

Wind tunnels are large cylindrical tubes where forced almost laminar air moving inside. The tunnels are used to imitate the functions of an object during flight. Researchers use wind tunnels to study more about how an aircraft wing will fly. In wind tunnel air moves around an object, making it exhibit like the object is really flying. Most of the time, powerful fans driven by electric motor move air through the tube [6]. Planes, cars, bikes, and many other moving objects are tested in wind tunnels to test aerodynamics or how an object moves through air at many speeds. Wind tunnels can be whole buildings which use powerful fans driven by electric motor to test life size objects, or small models, like the one you will build and test today [7]. The air moving in the region of the still object shows what would befall if the object were moving through the air. How the air steering can be studied in different ways? Smoke or dye can be added in the air which can be seen as it moves. Filaments can be attached to the object to display how the air is moving. Special instruments measuring device like manometer, aerodynamic weight balance are often attached which is using to measure the force of the air on the object.

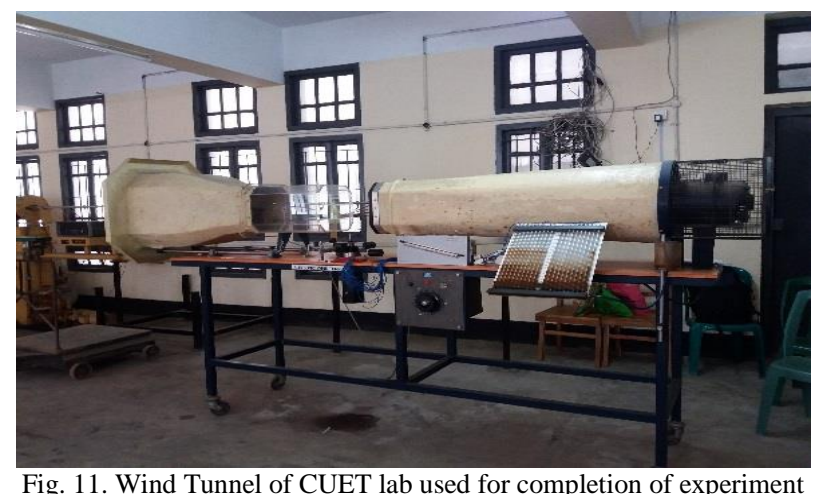

\section{F. Experimental Setup}

In this project work, we used a wind tunnel to explore the effect \& consequences of lift and drag force acting on an airfoil. A fluid (air) flowing around a body like airfoil, in this work an airfoil has a force exerted on it. Lift is a force which is defined to be the force component exerted by the airfoil that is perpendicular to the oncoming fluid flow direction [9]. The drag force is the opposite force of lift, which also defined as the force component of the fluiddynamic force parallel to the flow direction. We will trace how the angle of attack changes the amount of lift over an airfoil competence. The angle of attack $(\alpha)$ which is angle between air flows with respect to the chord line. The chord line is a straight line between the most onwards point and most after point of the body. We also studied the outcomes of velocity and pressure on lift, if the angle of attack is kept constant and velocity increased gradually as a result we would expect an increase and sufficient in lift force. We calculated the airfoil lift as a function of velocity [11]. The lift and drag coefficients are mostly dependent on the shape of the airfoil. NACA 64A012 mod, Elliptical wing (model) $\&$ Mosquito wing (wing) are non-symmetrical airfoil. The shapes and size of airfoil play a huge role on the amount of lift and drag generation and experienced during experiment. The prototype was equipped with 10 surface pressure taps. These pressure pipes were connected with the multi-tube manometer via $2 \mathrm{~mm}$ inner diameter of plastic tubes. Pressure was measured from recorded manometer height measurements using kerosene as working fluid.

\section{G. Pressure Distribution across the Airfoil}

Aerodynamic forces consequence of the pressure distribution over the surface of airfoil or wing. One fruitful way to calculate the aerodynamic forces which is use pressure taps to record the pressure distribution and to 
integrate the pressure distribution to find out the net theoretical lift force. For theoretical lift this integration is sib with the pressure distribution in the vertical direction while for drag the horizontal pressure distribution is important. You can see how the surface "pushes back" with a force against the pressure as interlude with incoming air, which always acts normal to the surface of airfoil. Surface bent is important two mechanisms are used to generate Lift. This is oft used for subsonic flying inflictions. The another step is to incline the airfoil at an angle allied to horizon, which is usually known as the "relative wind angle". For low values of this angle of attack, the fluid flow remains attached on both upper and lower foil surfaces. For higher angles of attack flow separation occurred that increased drag force with corresponding reduces lift force. Eventually, the airfoil reaches a stall $\&$ halt condition occurred where the pressure distribution over the airfoil on the top and bottom are equal.

\section{EXPERIMENTAL DATA}

\section{A. Theoretical Lift Force}

The theoretical lift force of NACA $64 \mathrm{~A} 012 \mathrm{mod}$ is 0.061 $\mathrm{N} / \mathrm{m} 2$ whereas the other two prototype airfoil of Elliptical wing \& Mosquito wing is $0.0165 \mathrm{~N} / \mathrm{m} 2$ and $0.005 \mathrm{~N} / \mathrm{m} 2$. This value indicates that the NACA 64A012 mod airfoil has the greater flying ability than other two prototype airfoil and also indicates that the prototype Elliptical wing is more flying efficient than prototype model Mosquito wing.
TABLE III: THEORETICAL LIFT OF NACA 64A012 MOD AIRFOIL

\begin{tabular}{cccccccc}
\hline \hline $\begin{array}{c}\text { Obs. } \\
\text { No }\end{array}$ & Lap no & 1 & 2 & 3 & 4 & 5 & $\begin{array}{c}\text { Lift } \\
\text { force } \\
\left(\mathrm{N} / \mathrm{m}^{2}\right)\end{array}$ \\
\hline $\begin{array}{c}\text { Curved } \\
\text { Surface }\end{array}$ & $\begin{array}{c}\text { Pressure } \\
\text { Head, mm } \\
\text { Pressure } \\
\text { Head, } \\
\text { Lowm }\end{array}$ & 9 & 9 & 8 & 6 & 8 & \\
Surface & 9 & 8 & 8 & 7 & \\
$\begin{array}{c}\text { Curved } \\
\text { Surface } \\
\text { Lower } \\
\text { surface }\end{array}$ & $\begin{array}{c}\text { Pressure } \\
\text { Pressure } \\
\left(\mathrm{N} / \mathrm{m}^{2}\right)\end{array}$ & 0.09 & 0.056 & 0.09 & 0.068 & 0.09 & 0.061 \\
& $\begin{array}{c}\text { Pressure } \\
\text { Difference }\end{array}$ & 0.034 & 0 & 0 & -.022 & 0.011 & \\
\hline \hline
\end{tabular}

\section{B. Comparison with the Analytical Values of those Airfoil}

Our main goal is to compare the analytical or numerical value of those prototype Elliptical wing, Mosquito wing \& NACA 64A012 mod airfoil. As we proceeding our project work firstly we evaluate the experimental value that we get from wind tunnel manometric height reading at different angle of attack $00,50,100,120,140,150$ respectively. For furthermore numerical \& statistical analysis we tested those prototype sketched airfoil pattern in simulation software like 'SOLIDWORKS' for actual value which gives also the information of velocity contour around those airfoils. These velocity contour indicates that how air flow interact with these airfoils and shearing force acting in this airfoil.

TABLE IV-A: EXPERIMENTAL RESULTS (ELLIPTICAL WING)

\begin{tabular}{|c|c|c|c|c|c|c|}
\hline $\begin{array}{c}\text { Angle of } \\
\text { Attack }\end{array}$ & $\begin{array}{l}\text { Lift, } \\
\text { L }\end{array}$ & $\begin{array}{c}\text { Drag, } \\
\text { D }\end{array}$ & $\mathrm{L} / \mathrm{D}$ & $\mathrm{C}_{\mathrm{L}}$ & $\mathrm{C}_{\mathrm{D}}$ & $\mathrm{C}_{\mathrm{L}} / \mathrm{C}_{\mathrm{D}}$ \\
\hline 0 & 0.028 & 0.06 & 0.46630 & 0.137 & 0.2938 & 0.46630 \\
\hline 5 & 0.045 & 0.064 & 0.70288 & 0.22 & 0.313 & 0.70288 \\
\hline 10 & 0.095 & 0.075 & 1.26667 & 0.46 & 0.3673 & 1.26667 \\
\hline 12 & 0.11 & 0.08 & 1.35550 & 0.53 & 0.391 & 1.35550 \\
\hline 14 & 0.12 & 0.085 & 1.41004 & 0.587 & 0.4163 & 1.41004 \\
\hline 15 & 0.145 & 0.105 & 1.38152 & 0.7101 & 0.514 & 1.38152 \\
\hline \multicolumn{7}{|c|}{ TABLE IV-B: SIMULATION RESULTS (ELLIPTICAL WING) } \\
\hline $\begin{array}{c}\text { Angle of } \\
\text { Attack }\end{array}$ & $\begin{array}{c}\text { Lift, } \\
\text { L }\end{array}$ & $\begin{array}{c}\text { Drag, } \\
\text { D }\end{array}$ & $\mathrm{L} / \mathrm{D}$ & $\mathrm{C}_{\mathrm{L}}$ & $\mathrm{C}_{\mathrm{D}}$ & $\mathrm{C}_{\mathrm{L}} / \mathrm{C}_{\mathrm{D}}$ \\
\hline 0 & 0.028 & 0.06 & 0.46630 & 0.137 & 0.2938 & 0.46630 \\
\hline 5 & 0.045 & 0.064 & 0.70288 & 0.22 & 0.313 & 0.70288 \\
\hline 10 & 0.095 & 0.075 & 1.26667 & 0.46 & 0.3673 & 1.26667 \\
\hline 12 & 0.11 & 0.08 & 1.35550 & 0.53 & 0.391 & 1.35550 \\
\hline 14 & 0.12 & 0.085 & 1.41004 & 0.587 & 0.4163 & 1.41004 \\
\hline 15 & 0.145 & 0.105 & 1.38152 & 0.7101 & 0.514 & 1.38152 \\
\hline \multicolumn{7}{|c|}{ TABLE IV-C: EXPERIMENTAL RESULTS (MOSQUITO WING) } \\
\hline $\begin{array}{l}\text { Angle } \\
\text { of } \\
\text { Attack }\end{array}$ & Lift, L & $\begin{array}{l}\text { Drag, } \\
\text { D }\end{array}$ & $\mathrm{L} / \mathrm{D}$ & $\mathrm{C}_{\mathrm{L}}$ & $\mathrm{C}_{\mathrm{D}}$ & $\mathrm{C}_{\mathrm{L}} / \mathrm{C}_{\mathrm{D}}$ \\
\hline 0 & 0.001 & 0.004 & 0.251 & 0.00489 & 0.0195 & 0.251 \\
\hline 5 & 0.0038 & 0.0042 & 0.9048 & 0.00186 & 0.0205 & 0.905 \\
\hline 10 & 0.07 & 0.0043 & 16.2791 & 0.342 & 0.02106 & 16.28 \\
\hline 12 & 0.088 & 0.0052 & 16.9231 & 0.4312 & 0.0254 & 16.92 \\
\hline 14 & 0.0104 & 0.007 & 1.4857 & 0.0509 & 0.034 & 1.486 \\
\hline 15 & 0.0138 & 0.073 & 0.18904 & 0.0675 & 0.357 & 0.189 \\
\hline
\end{tabular}


TABLE IV-D: SIMULATION RESULTS (MOSQUITO WING)

\begin{tabular}{ccccccc}
\hline \hline AOA & Lift, L & Drag, D & L/D & $\mathrm{C}_{\mathrm{L}}$ & $\mathrm{C}_{\mathrm{D}}$ & $\mathrm{C}_{\mathrm{L}} / \mathrm{C}_{\mathrm{D}}$ \\
\hline 0 & 0.00021 & 0.00057 & 0.3684 & 0.00102 & 0.0027 & 0.37 \\
5 & 0 & 0.00045 & 0 & 0 & 0.0022 & 0 \\
10 & 0.0011 & 0.00075 & 1.467 & 0.00538 & 0.0036 & 1.47 \\
12 & 0.00134 & 0.00057 & 2.3509 & 0.0065 & 0.0027 & 2.35 \\
14 & 0.0017 & 0.0083 & 0.20482 & 0.0008 & 0.00391 & 0.21 \\
15 & 0.0021 & 0.001 & 2.10 & 0.0102 & 0.0048 & 2.10 \\
\hline \hline
\end{tabular}

TABLE IV-E: EXPERIMENTAL RESULTS (NACA 64A012)

\begin{tabular}{|c|c|c|c|c|c|c|}
\hline $\begin{array}{c}\text { Angle of } \\
\text { Attack }\end{array}$ & Lift, L & Drag, D & $\mathrm{L} / \mathrm{D}$ & $\mathrm{C}_{\mathrm{L}}$ & $C_{D}$ & $\mathrm{C}_{\mathrm{L}} / \mathrm{C}_{\mathrm{D}}$ \\
\hline 0 & 0.03 & 0.09 & 0.333 & 0.1469 & 0.4408 & 0.333 \\
\hline 5 & 0.00053 & 0.001 & 0.531 & 0.04702 & 0.0048 & 0.531 \\
\hline 10 & 0.002 & 0.0015 & 1.333 & 0.0097 & 0.056 & 1.333 \\
\hline 12 & 0.00231 & 0.0012 & 1.925 & 0.00113 & 0.0058 & 1.925 \\
\hline 14 & 0.0024 & 0.0013 & 1.8462 & 0.011 & 0.00636 & 1.8462 \\
\hline 15 & 0.0025 & 0.00135 & 1.852 & 0.0122 & 0.00661 & 1.852 \\
\hline \multicolumn{7}{|c|}{ TABLE IV-F: SIMULATION RESULTS (NACA 64A012) } \\
\hline $\begin{array}{c}\text { Angle } \\
\text { of } \\
\text { Attack }\end{array}$ & Lift, L & Drag, D & $\mathrm{L} / \mathrm{D}$ & $\mathrm{C}_{\mathrm{L}}$ & $\mathrm{C}_{\mathrm{D}}$ & $\mathrm{C}_{\mathrm{L}} / \mathrm{C}_{\mathrm{D}}$ \\
\hline 0 & 0 & 0 & 0 & 0 & 0 & 0 \\
\hline 5 & 0.00012 & 0.0002 & 0.6 & 0.00058 & 0.00094 & 0.6 \\
\hline 10 & 0.00039 & 0.00012 & 3.250 & 0.00191 & 0.00058 & 3.250 \\
\hline 12 & 0.0005 & 0.00014 & 3.3571 & 0.0023 & 0.0007 & 3.3571 \\
\hline 14 & 0.0006 & 0.00023 & 2.6522 & 0.0030 & 0.0012 & 2.6522 \\
\hline 15 & 0.0007 & 0.0003 & 3.0660 & 0.00318 & 0.00103 & 3.06604 \\
\hline
\end{tabular}

\section{RESUlTS AND DISCUSSION}

The target was set as per objective and the simulation was done for a number of angle of attack starts from $0^{\circ}$ to $15^{\circ}$. Turbulent and laminar flow were started to separate by a point of transition or separation point; as the angle of attack is increased with corresponding relative velocity and temperature, the portion of the upper airflow that is turbulent also increases. Flow separation across airfoil occurs when the boundary layer tracing far enough contra and converse pressure gradient on the swiftness of the boundary layer correlated to the object falls almost to zero. The fluid flow becomes separated from the adjacent surface of the object and instead of taking the conjugation of eddies and vortices. This flow separation can oft result in increased drag and corresponding lift, particularly pressure drag which is generated by the pressure differential distribution between the leading and trailing surfaces of the airfoil as it treks through the fluid over airfoil. There are many parameters like Reynolds number, thickness ratio, Mach number, angle of attack, drag polar equation, Prandtl's number etc. But here performance of the airfoil was calculated by only considering lift and drag force for different angle of attack with corresponding air velocity with same temperature. From lift and drag coefficient lift and drag force was measured also lift-drag ratio calculated as well.

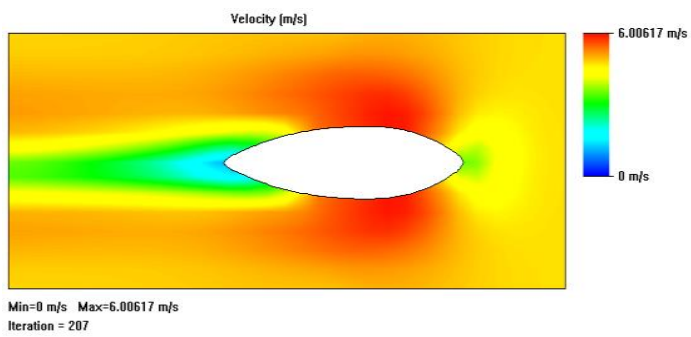

(a)

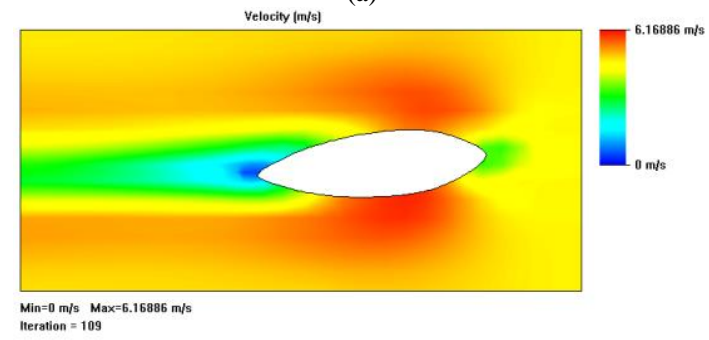

(b)

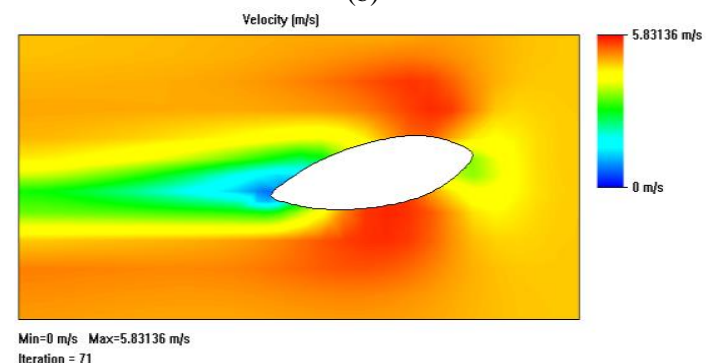

(c)

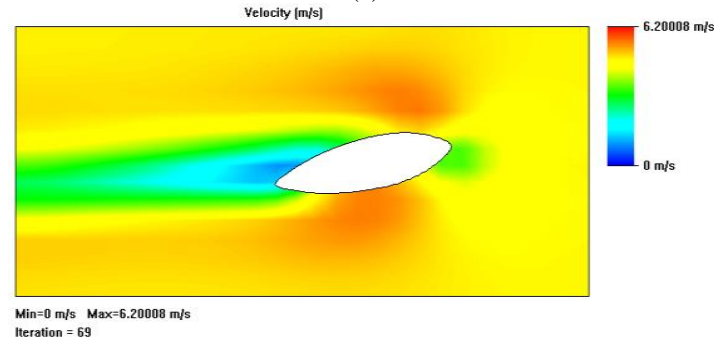

(d)

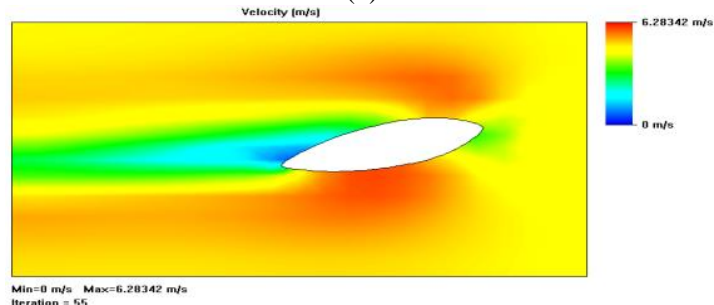

(e)

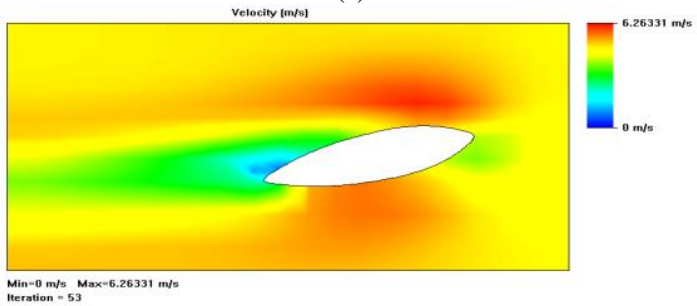

(f)

Fig. 12. Velocity distribution of Elliptical wing (model) for angle of attack (a) $0^{0}$ (b) $5^{0}$ (c) $10^{0}$ (d) $12^{\circ}$ (e) $14^{0}$ (f) $15^{0}$ respectively 


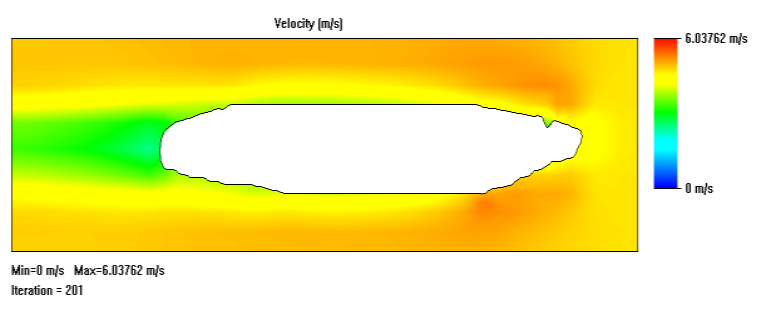

(a)

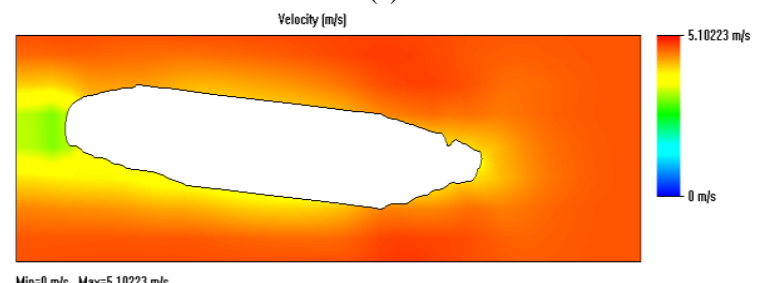
Min $=0 \mathrm{~m} / \mathrm{s} \mathrm{Max}=5.10223 \mathrm{~m} / \mathrm{s}$
theration $=187$

(b)

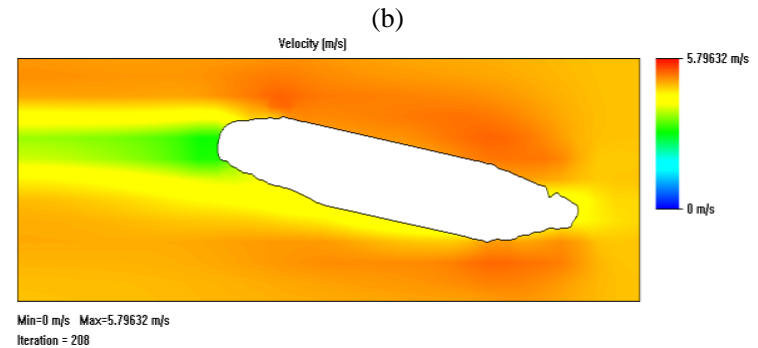

(c)

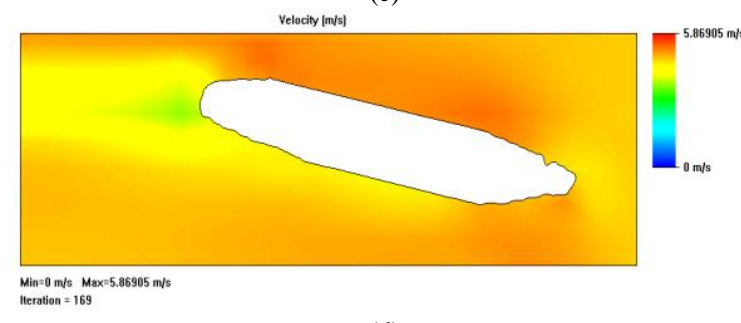

(d)

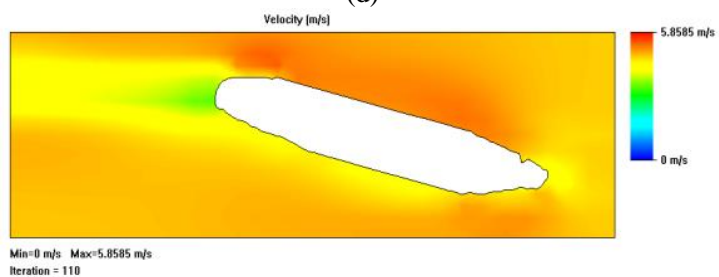

(e)

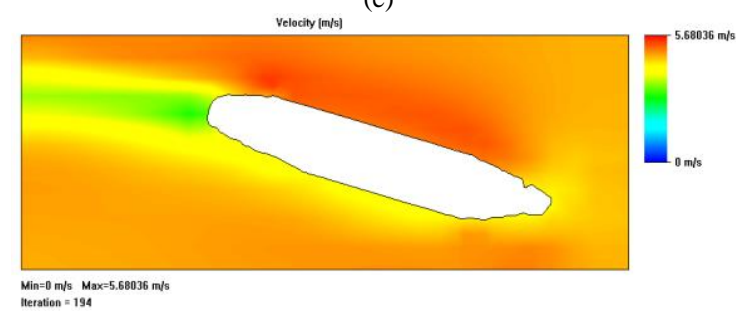

(f)

Fig. 13. Velocity distribution of Mosquito wing for angle of attack (a) $0^{0}$ (b) $5^{0}$ (c) $10^{0}$ (d) $12^{0}$ (e) $14^{0}$ (f) $15^{0}$ respectively

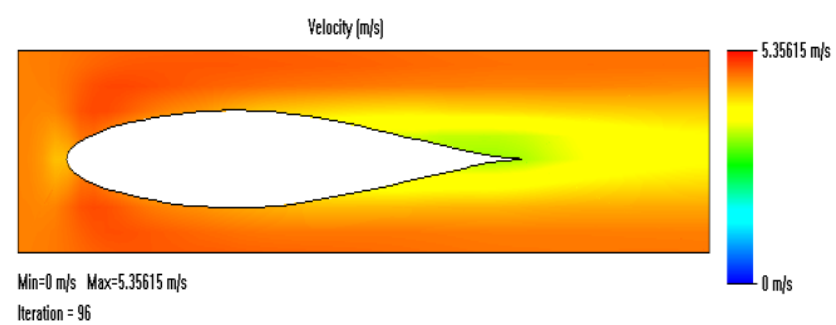

(a)

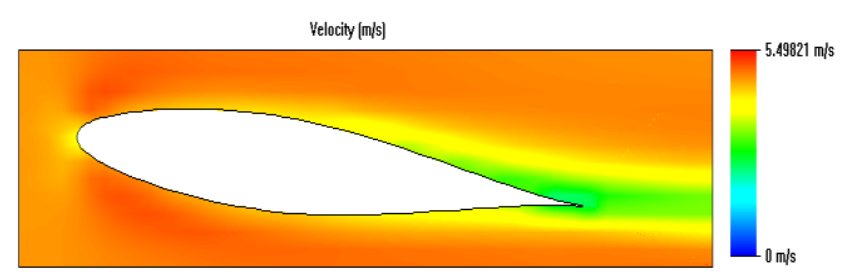

Min $=0 \mathrm{~m} / \mathrm{s} \quad$ Max $=5.49821 \mathrm{~m} / \mathrm{s}$

Iteration $=237$

(b)

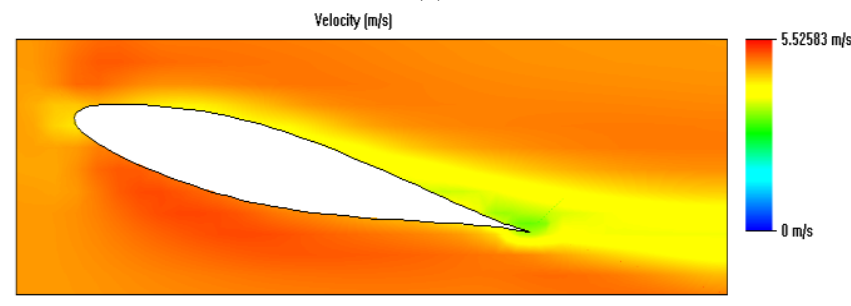

Min $=0 \mathrm{~m} / \mathrm{s} \quad \mathrm{Max}=5.52583 \mathrm{~m} / \mathrm{s}$

Iteration $=65$

(c)

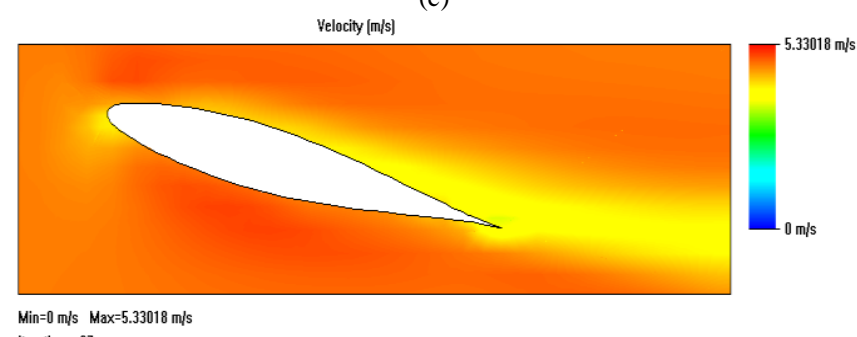

(d)

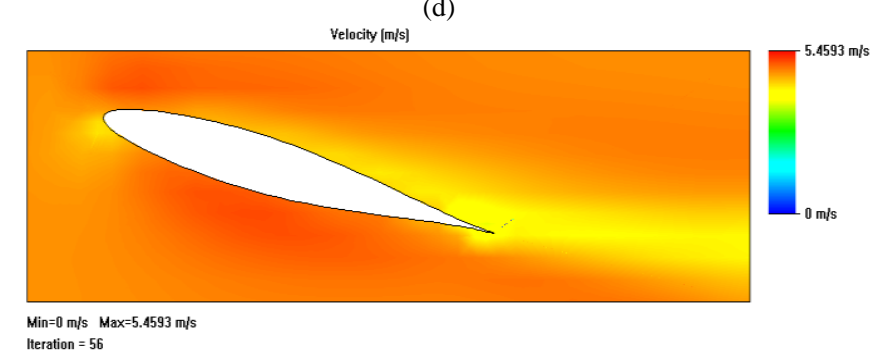

(e)

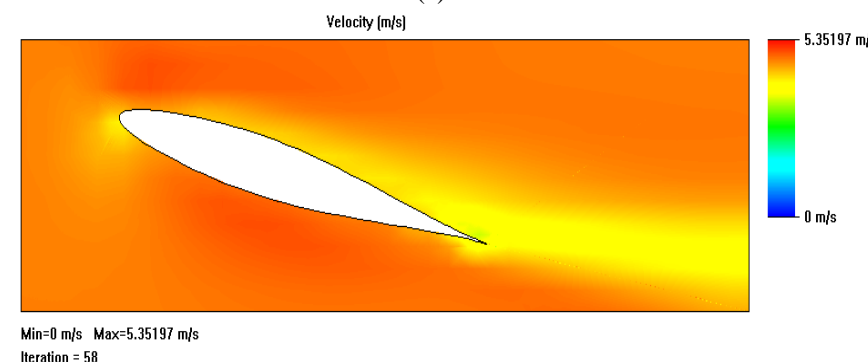

(f)

Fig. 14. Velocity distribution of NACA 64A012 mod airfoil for angle of attack (a) $0^{\circ}$ (b) $5^{0}$ (c) $10^{\circ}$ (d) $12^{0}$ (e) $14^{0}$ (f) $15^{0}$ respectively

Normally for negative pressure for upper surface manometer reading is positive and lower surface manometer reading is negative. But in this experiment for all tapping points manometric readings were positive. This occurred for the whole size and shape that gives rise to manometric pressure. Therefore, the whole curve shifts upwards while plotting the values. The lift-to-drag ratio L/D is a measure of the aerodynamic efficiency of an airplane or the aircraft particle. It only makes sense that maximum aerodynamics efficiency should be lead to minimum thrust required. So, it is important to show the lift-to-drag ratio L/D of those three airfoil. 


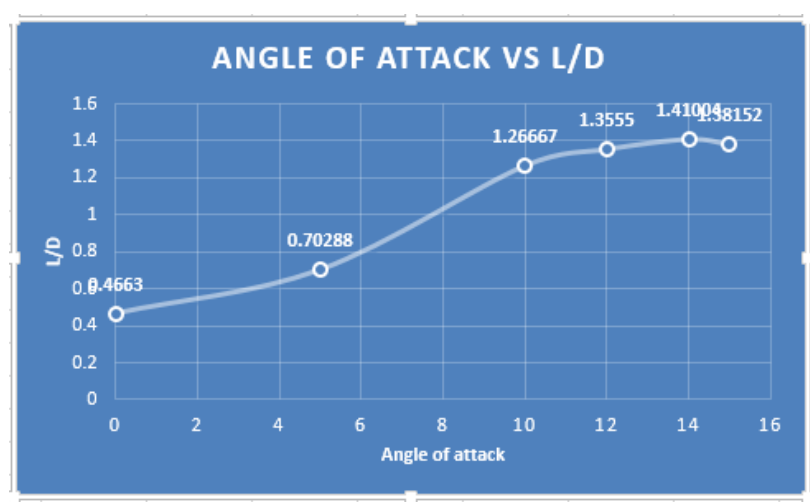

(i)

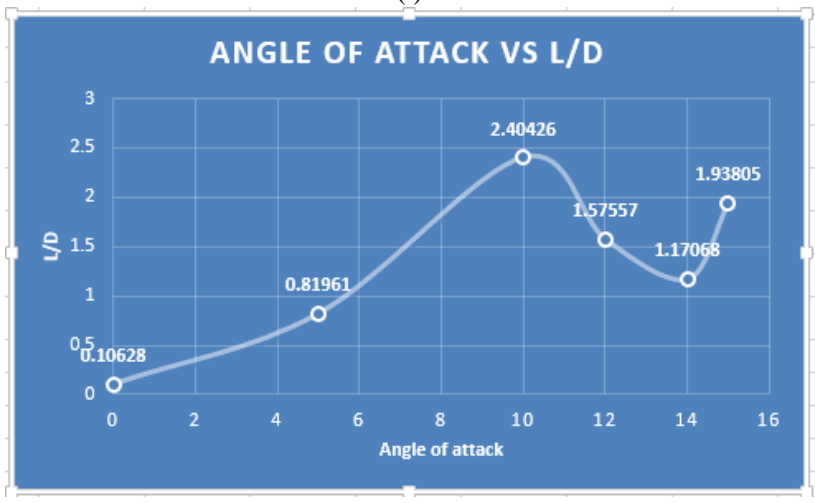

(ii)

Fig. 15. Angle of attack vs lift-to-drag ratio L/D for Elliptical wing (i) experimental result (ii) simulation result

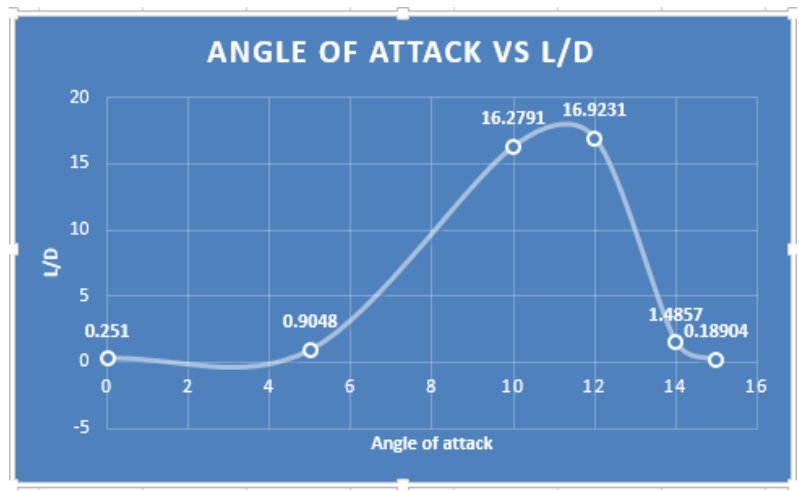

(i)

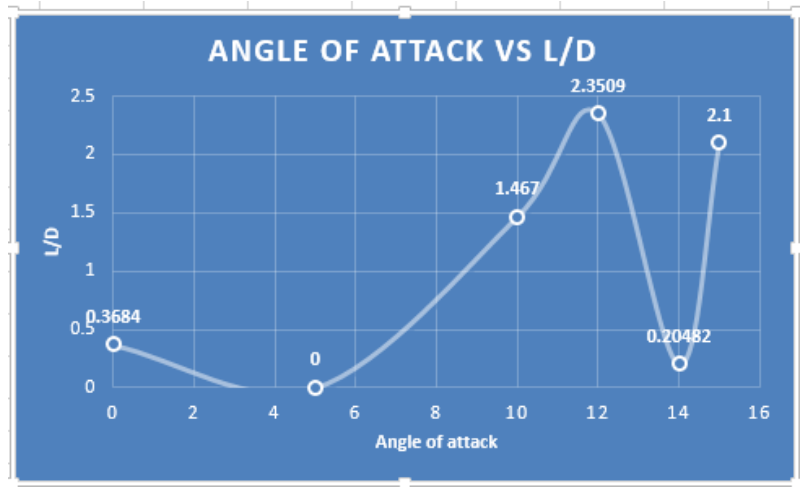

(ii)

Fig. 16. Angle of attack vs lift-to-drag ratio L/D for Mosquito wing (i) experimental result (ii) simulation result

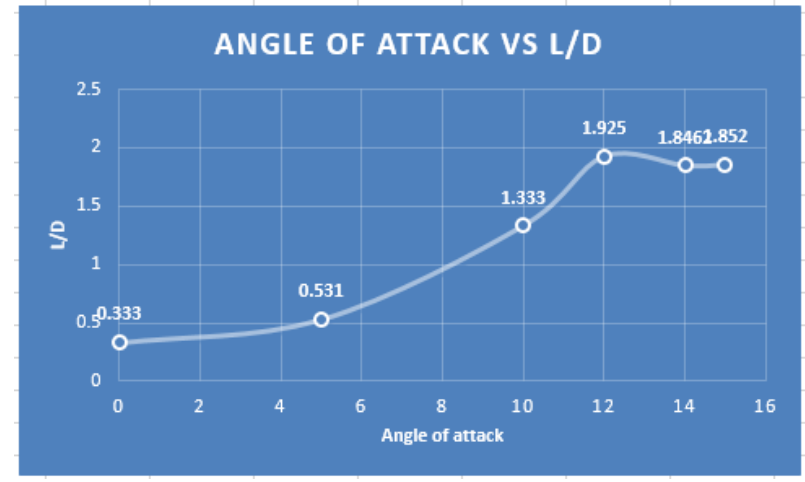

(i)

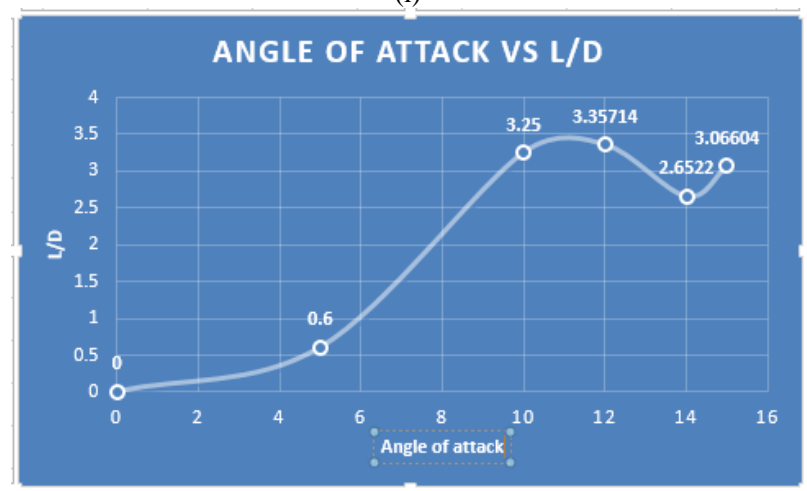

(ii)

Fig. 17. Angle of attack vs lift-to-drag ratio L/D for NACA 64A012 mod airfoil (i) experimental result (ii) simulation result

From graph we can see that the lift-to-drag ratio L/D which known as aerodynamic efficiency is greater in NACA 64A012 mod airfoil then the other two model like Elliptical wing \& Mosquito wing. So we can assume that NACA 64A012 airfoil has approximately higher fly ability than prototype Elliptical wing \& Mosquito wing. The results showed the factual influence of the aforecited unsteady condition parameters corresponding to the maximum lift and drag co-efficient. The parameters increase or decrease the aerodynamic forces with respect to the optimum peak values depending on the surrounding fluid flow composition [13]. During our experiment we use analog or manual wind tunnel to test pressure distribution across the airfoil, lift and drag force of it. Using this analog wind tunnel we have some experimental and analytical procedure error. On the Other hand, the prototype model wing that we made is not proper in dimension and corresponding airfoil geometry. This is also a reason why we have some experimental error over numerical value or actual value. Besides, the wind tunnel we used was worn out (Mach no. 0.3) and the data collection technique has become very ineffective. Today's wind tunnel device uses automatic weight balance, digital force measurement system and pressure sensors for pressure measurement and that wind tunnel system get value that auto plot in the graph. In most of the case they are integrated with a computer via software with a printer.

\section{CONCLUSION}

Wing is the part and parcel of aircraft flying. More accurate shape and size of airfoil more stable in flying and clearly showing aerodynamic characteristics. For choosing NACA 64A012 mod airfoil is that L-39 Albatross lite combat trainer aircraft of Bangladesh Air Force (BAF) using 
this type of airfoil. On the other hand, choosing of elliptical wing because during era of WW II 'The Supermarine Spitfire' which has greater aerodynamic performance at that time using this elliptical wing. Lastly, choosing of mosquito wing because this type insect flying in nature with the help of flapping its wing which create thrust to stable during fly. Since Lift to Drag is known as the aerodynamic efficiency factor that's why we are only showing $\mathrm{L} / \mathrm{D}$ ratio with respect to different angle of attack of those three model wing like Elliptical wing, Mosquito wing and NACA 64A012 mod airfoil. The test corroborated to the high lift/drag ratio (Aerodynamic Efficiency) and the high maximum lift coefficient $\left(\mathrm{C}_{\mathrm{L}}\right)$ but the airfoil was found to be a little sensitive to leading edge surface roughness.

\section{ACKNOWLEDGMENT}

The authors would like to be obliged to Chittagong University of Engineering and Technology for providing laboratory facilities and financial assistance.

\section{REFERENCES}

[1] http://www.codecogs.com/library/engineering/aerodynamics/basicaerodynamics-theory.php

[2] http://web.mit.edu/16.00/www/aec/flight.html

[3] Fundamental of Aerodynamics/John D Anderson/Chapter3

[4] http://faculty.dwc.edu/.../chapter5,'Daniel Webster College'; Wing Design

[5] http://www.airfoiltools.com/airfoil/details?airfoil=n64012a-irfoil

[6] http://www.nasa.gov/audience/k-4/stories/nasa-knows/what-are-windtunnel-k4.html

[7] http://www.education.com/science-fair/article/physics_experimentswind-tunnel/

[8] Md. Nesar Ali. Study on Bird's \& Insect's Wing Aerodynamics and Comparison Its Analytical Value with Standard Airfoil.2017. AIP Conference Proceeding: Volume 1851,020056.

[9] Md. Nesar Ali. Study on flow over finite wing with respect to F-22 raptor, Supermarine Spitfire, F-7 BG aircraft wing and analyze its stability performance and experimental values.2017. AIP Conference Proceeding: Volume 1851,020079.

[10] Dr. Md. Mahbubul Alam. A Comparative Studies on various model Bird's wing \& standard airfoil \& also track down the most effective airfoil using CFD solver software. 2017. ICMERE conference proceeding, 2017

[11] Dr. A.B.M Toufique Hasan. Study on Bird's flapping wing aerodynamics and compared its analytical values with NACA 64A012 mod Airfoil. 2016. ICMIEE Conference proceeding 2016.
[12] Rashed Ahammad. Performance Test of NACA 2412 Airfoil. 2015. ICMERE Conference Proceeding, 2015.

[13] M.R. Amiralai. An investigation into the effects on unsteady parameters on the aerodynamics of a low Reynolds number pitching airfoil. 2010. Journal of Fluids and Structure 26 (2010), 979-993.

[14] M.A. Ashraf. Reynolds number, thickness and camber effect on flapping airfoil propulsion. 2011. Journal of Fluids and Structures 27 (2011) 145-160.

[15] Jiyu Sun. The structure and mechanical properties of dragonfly wings and their role on fly ability. 2012. Journal of Fluids and Structure 340, (2012), 3-17

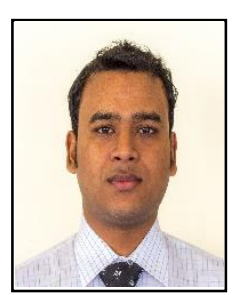

Md. Nesar Ali was born in Bangladesh. He obtained $\mathrm{BSc}$ in Mechanical Engineering from Chittagong University of Engineering \& Technology (CUET) in 2017. He has published a number of publication on different Peer reviewed article international research journal (AIP) and also published many conference proceedings in many international conference which held in Bangladesh. His field of interest includes Aerodynamics, Computational Fluid Dynamics, Renewable energy, sustainable energy, Thermodynamics, Heat Transfer and Mechatronics.

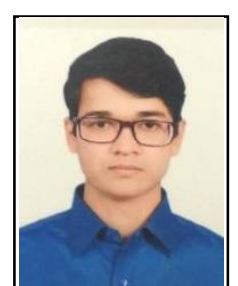

Md. Mostafizur Rahman Komol was born in Bangladesh. He obtained BSc in Mechanical Engineering from Khulna University of Engineering \& Technology (KUET) in 2017. He has published a number of conference proceedings in many international conference held in Bangladesh. His field of interest includes Control engineering, Aerodynamics, Mechatronics, Computational Fluid dynamics, engineering Mechanics, Thermodynamics Robotics and Renewable Energy.

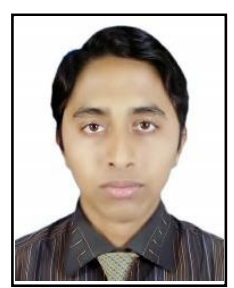

Mohammad Takiuddin Saki was born in Bangladesh. He obtained BSc in Mechanical Engineering from Chittagong University of Engineering \& Technology (CUET) in 2010. He is working now as "Senior Instructor" at Bangladesh Institute of Marine Technology (BIMT) since 2016 and Head of the Department, Shipbuilding Technology, BIMT. He has more than five years of working experience in Ship building industry of Bangladesh. His field of interest includes Fluid Dynamics, Engineering Mechanics, Thermodynamics, Heat Transfer, Automation \& Automobile Engineering, Engineering Operation Management, Ship Building \& Ship Propulsion System, Mechanical and Electrical System of water vehicles and Renewable \& Sustainable Energy. 